\title{
Significance of the viral load of high-risk HPV in the diagnosis and prediction of cervical lesions: a retrospective study
}

\author{
Yang Liu ${ }^{1 \dagger}$, Changjun $\mathrm{Xu}^{2 \dagger}$, Jing Pan ${ }^{3}$, Chunyi Sun ${ }^{3}$, Honglin Zhou ${ }^{3 *}$ and Yushi Meng ${ }^{1 *}$
}

\begin{abstract}
Background: The significance of HPV viral load in the detection of cervical lesions is still controversial. This study analyzed the correlation between the high-risk HPV viral load and different cervical lesion degrees.

Methods: This retrospective study included women positive for high-risk HPV DNA and screened for cervical lesions between 01/2015 and 06/2018. The high-risk HPV DNA load was measured by the second-generation Hybrid Capture technology and classified as low, moderate, and high. Colposcopy and biopsy were performed in all patients. The patients were grouped as normal, cervical intraepithelial neoplasia (CIN) grade 1, CIN grade 2, CIN grade 3, and cervical cancer. Multivariable logistic regression was performed to explore the association between high-risk HPV DNA load and cervical lesions. The odds ratios (ORs) represent the odds for increasing from low to high viral load.

Results: Finally, 265 patients were grouped as normal $(n=125), \operatorname{CIN} 1(n=51), \operatorname{CIN} 2(n=23), \operatorname{CIN} 3(n=46)$, and cervical cancer $(n=20)$. Among them, $139(52.5 \%)$ had a low viral load, 90 (34.0) had a moderate viral load, and 36 (13.4\%) had a high viral load. Taking the normal control group as a reference, a high viral load was an independent factor for $\mathrm{CIN} 1(\mathrm{OR}=3.568,95 \% \mathrm{Cl}: 1.164-10.941, P=0.026)$, CIN $2(\mathrm{OR}=6.939,95 \% \mathrm{Cl}: 1.793-26.852, P=0.005), \mathrm{CIN} 3$ $(\mathrm{OR}=7.052,95 \% \mathrm{Cl}: 2.304-21.586, P=0.001)$, and cervical cancer $(\mathrm{OR}=8.266,95 \% \mathrm{Cl}: 2.120-32.233, P=0.002)$.
\end{abstract}

Conclusions: Among women who underwent cervical biopsy, higher high-risk HPV viral load in cervical lesions was associated with a higher risk of high-grade cervical lesions.

Keywords: Cervical cancer, Cervical intraepithelial neoplasia, Human papillomavirus, Viral load, Predictive value

\section{Background}

Cervical cancer is the fourth major malignant tumor in women worldwide [1]. In 2018, there were an estimated 570,000 new cases of cervical cancer in the world and 311,000 deaths, with $85 \%$ of the new cases being in developing countries [2]. In China, the incidence of cervical

\footnotetext{
*Correspondence: km20150515@163.com; 13708704452@163.com

${ }^{\dagger}$ Yang Liu and Changjun Xu contributed equally to this work

${ }^{1}$ Department of Reproduction, The Second Affiliated Hospital

of Kunming Medical University, Kunming, China

${ }^{3}$ Department of Gynecology, The Second Affiliated Hospital of Kunming

Medical University, No.374 Yunnan-Burma Avenue, Kunming 650101,

China

Full list of author information is available at the end of the article
}

cancer has been increasing in recent years, but the mortality has been decreasing [3-5], probably because of the implementation of screening and early treatment of cervical lesions [6].

Human papillomavirus (HPV) infection can lead to cervical precancerous lesions and cervical cancer [7]. Active papillomavirus infection occurs when infected basal cells replicate and fill an area [8]. Persistent HPV infection results in squamous intraepithelial lesions graded as cervical intraepithelial neoplasia (CIN) 1 , CIN 2, and CIN 3 according to how much epithelium is impacted [8]. Different types of HPV have different potentials of causing cervical cancer. High-risk HPV is the main cause of

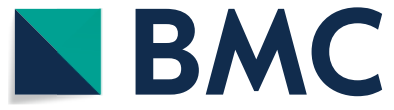

(c) The Author(s) 2021. Open Access This article is licensed under a Creative Commons Attribution 4.0 International License, which permits use, sharing, adaptation, distribution and reproduction in any medium or format, as long as you give appropriate credit to the original author(s) and the source, provide a link to the Creative Commons licence, and indicate if changes were made. The images or other third party material in this article are included in the article's Creative Commons licence, unless indicated otherwise in a credit line to the material. If material is not included in the article's Creative Commons licence and your intended use is not permitted by statutory regulation or exceeds the permitted use, you will need to obtain permission directly from the copyright holder. To view a copy of this licence, visit http://creativecommons.org/licenses/by/4.0/. The Creative Commons Public Domain Dedication waiver (http://creativecommons.org/publicdomain/zero/1.0/) applies to the data made available in this article, unless otherwise stated in a credit line to the data. 
cervical cancer. High-risk HPV subtypes such as HPV16, $18,31,33,35,39,45,51,52,56$, and 59 are closely associated (in decreasing order of oncogenic potential) with the occurrence of cervical cancer. This association is seen throughout the world [9], but there are some regional differences in the prevalence of the different HPV subtypes $[10,11]$. The high-risk HPV viral load indicates the activity of HPV-DNA in the body [12, 13]. Studies showed that the type of HPV infection is closely related to the severity of cervical lesions and treatment prognosis [911], but there are inconsistent results among the studies on the correlation between the HPV viral load and the severity of cervical lesions [12-18]. Indeed, Xi et al. [12] reported that HPV16 viral load was associated with CIN 3 only, while Berggrund et al. [13] showed high-risk HPV viral load was associated with CIN $2+$ lesions. Dong et al. [14] reported that the HPV 16/31/33/52/58 viral load was associated with cervical lesion severity. Del Rio-Ospina et al. [15] reported that a low HPV16 viral load was more associated with cervical lesions than a high HPV16 load. Shen et al. [16] reported an association between high-risk HPV viral load and cervical lesion severity. Long et al. [18] reported that HPV16/33/58 viral load was associated with premalignant cervical lesion severity. Hence, at present, the correlation between the HPV viral load and cervical lesions has not been determined, and the significance of the HPV viral load in the detection and treatment of cervical lesions is still controversial $[16,18]$.

Therefore, the objective of this study was to investigate the changes in high-risk HPV viral load in patients with different degrees of cervical lesions to clarify the correlation between the viral load of HPV and cervical lesions and to explore the clinical value of high-risk HPV viral load for the predictive diagnosis of cervical cancer.

\section{Methods}

\section{Study design and patients}

This retrospective study included patients who first visited the Gynecology Clinic of the Second Affiliated Hospital of Kunming Medical University between January 2015 and June 2018. All methods were performed in accordance with the Declaration of Helsinki and the relevant guidelines and regulations. This study was approved by the ethics committee of the Second Affiliated Hospital of Kunming Medical University. As a retrospective study, informed consent was exempted by the ethics committee of the Second Affiliated Hospital of Kunming Medical University.

The included women were women with a history of sexual activity and who spontaneously sook screening. For HPV-negative patients, re-screening for HPV in 3-5 years or anytime in the presence of symptoms was recommended. The inclusion criteria were (1) patients with positive HPV-DNA who underwent cervical cancer screening according to the latest version of the American College of Obstetricians and Gynecologists (ACOG) guidelines for cervical cancer screening and prevention practice [19], and (2) patients with complete colposcopy and pathological biopsy to determine the degree of lesions. The exclusion criteria were (1) previous positive HPV test, (2) history of treatment for cervical disease, and (3) incomplete data.

\section{Data collection and grouping}

The age of the patients, the HPV-DNA viral load, and the pathological degree of cervical lesions at the time of screening were obtained from the clinical records. The patients were divided into five groups: normal group, CIN grade 1 group, CIN grade 2 group, CIN grade 3 group, and invasive cervical cancer group.

\section{Detection of HPV-DNA load}

The second generation of the Hybridized Capture II gene hybridization signal amplification system from Digene Co. (Gaithersburg, MD, USA) was used to detect the content of HPV-DNA in the samples. That assay can detect 13 types of high-risk HPV subtypes simultaneously. All assays were strictly performed according to the manufacturer's instructions. The relative light units (RLUs) and positive control values (CO) of the samples were detected. The ratio of the RLU to the CO value of the positive standard was used to indicate the viral load. $\mathrm{RLU} / \mathrm{CO}<1.0$ was considered a negative result. RLU/ $\mathrm{PC} \geq 1.0$ was considered a positive result, which means that the amount of HPV-DNA per ml of sample was $>1.0$ pg. According to Lorincz et al. [20], the viral load of high-risk HPV DNA can be classified into three levels: low viral load (1.00-99.99 RLU/CO), moderate viral load (100.00-999.00 RLU/CO), and high viral load ( $\geq 1000.00$ RLU/CO).

\section{Pathological results}

A colposcopy biopsy was performed after the diagnosis by a specialist gynecologist. The cervix, vagina, and vulva were examined at the same time. Each quadrant of the cervix was assessed. The basic principles of direct biopsy or quadrant biopsy were followed. Multi-point biopsies were taken in the vinegar white area and iodine-stained suspected lesion area and were sent directly for pathological examination. If no abnormality were found under the microscopic examination in each quadrant, samples would be taken at the squamous columnar junction or the transformation area at 3, 6, 9 and 12 o'clock of the cervix, and a sample would be taken by cervical curettage. The specimens taken by colposcopy were submitted to the pathology department of the same hospital for 
histopathological examination and immunohistochemistry if necessary. The final cervical pathological diagnosis was determined after quality control by two pathologists. The results were presented according to normal (no squamous epithelial lesions), CIN grade 1, CIN grade 2, CIN grade 3 , and cervical cancer.

\section{Statistical analysis}

SPSS 24.0 (IBM, Armonk, NY, USA) was used for data processing and statistical analysis. Categorical data were presented as frequencies and percentages and analyzed using the chi-square test or Fisher's exact test, as appropriate. The continuous data were tested for normal distribution using the Kolmogorov-Smirnov test and analyzed using the Student $t$-test or ANOVA with the LSD post hoc test. Unconditional logistic regression analysis was performed for univariable and multivariable analyses to calculate the odds ratio (OR) and 95\% confidence interval (CI) for the presence of cervical lesions in different viral load levels, using the normal group as the reference. $P$-values $<0.05$ were considered statistically significant.

\section{Results}

\section{Characteristics of the patients}

A total of 11,422 patients were screened for cervical cancer using the Hybrid Capture II system, and 1542 (13.5\%) were positive for HPV. Among them, 385 patients underwent colposcopy, and then 265 underwent cervical biopsy. Therefore, 265 patients, aged 20-73, were included in this study: 125 in the normal group, 51 in the CIN grade 1 group, 23 in the CIN grade 2 group, 46 in the CIN grade 3 group, and 20 in the cervical cancer group. The patients in the cervical cancer group were significantly older than the patients in the normal, CIN grade 1 , and CIN grade 2 groups (all $P<0.05$ ) (Table 1 ).

\section{HPV-DNA loads and correlation with pathological types}

Among the 265 patients, 139 (52.5\%) had a low viral load, 90 (34.0) had a moderate viral load, and 36 (13.4\%) had a high viral load. There were significant differences in viral load among the five pathological groups $(P<0.001)$. The viral load of patients in the CIN grade 3 and cervical cancer groups was higher than that of patients in the normal group, but there were no significant differences among the other groups (Table 2).

Taking the normal control group as a reference, the correlations between all cervical lesions and viral load were analyzed and compared using multivariable analyses. The results showed that the viral load was an independent risk factor for the occurrence of CIN grade 1 and CIN grade 2 (CIN I: high load, OR $=3.568,95 \%$ CI: 1.164 10.941, $P=0.026$; CIN II: high load, OR $=6.939,95 \% \mathrm{CI}$ : 1.793-26.852, $P=0.005$ ), but age was not an independent factor (all age groups $P>0.05$ ). For CIN grade 3 , age still was not an independent factor, but a moderate load of HPV (OR $=2.852,95 \%$ CI: 1.322-6.152, $P=0.008)$ and a high load of HPV (OR=7.052, 95\% CI: 2.304-21.586, $P=0.001)$ were independent risk factors. For cervical cancer, age was not associated, while high-load HPV

Table 1 Characteristics of the patients

\begin{tabular}{|c|c|c|c|c|c|c|}
\hline Characteristic, n (\%) & $\begin{array}{l}\text { Normal group } \\
(n=125)\end{array}$ & CIN I group $(n=51)$ & CIN II group $(n=23)$ & CIN III group $(n=46)$ & $\begin{array}{l}\text { Cervical cancer } \\
(\mathrm{n}=20)\end{array}$ & $P$ \\
\hline $\begin{array}{l}\text { Age (years old), } \\
\text { median (IQR) }\end{array}$ & $38(30,47)^{*}$ & $40(29.5,46)^{*}$ & $34(29,40.5)^{*}$ & $44(34,50)$ & $50(42.5,54.5)$ & $<0.001$ \\
\hline
\end{tabular}

${ }^{*} P<0.05$ versus the cervical cancer group

CIN Cervical intraepithelial neoplasia, IQR interquartile range

Table 2 Viral load of HPV-DNA in groups with different pathological results

\begin{tabular}{|c|c|c|c|c|c|c|}
\hline HPV-DNA load & $\begin{array}{l}\text { Normal group } \\
(n=125)\end{array}$ & CIN I group $(n=51)$ & CIN II group $(n=23)$ & $\begin{array}{l}\text { CIN III group } \\
(n=46)\end{array}$ & $\begin{array}{l}\text { Cervical cancer } \\
(n=20)\end{array}$ & $P$ \\
\hline $\begin{array}{l}\text { HPV-DNA viral load } \\
\text { RLU/CO, Median (IQR) }\end{array}$ & $48.52(4.16,180.87)$ & $156.34(10.54,578.08)$ & $159.13(36.19,701.465)$ & $\begin{array}{l}266.87(16.56 \\
958.13)^{*}\end{array}$ & $\begin{array}{l}307.005(72.76 \\
1386.075)^{*}\end{array}$ & $<0.001$ \\
\hline Low load group, n (\%) & $82(65.6 \%)$ & $24(47.1 \%)$ & $10(43.5 \%)$ & $16(34.8 \%)^{*}$ & $7(35 \%)^{*}$ & $<0.001$ \\
\hline $\begin{array}{l}\text { Medium load group, } \\
\text { n (\%) }\end{array}$ & $36(28.8 \%)$ & $19(37.2 \%)$ & $8(34.8 \%)$ & $20(43.5 \%)$ & $7(35 \%)$ & - \\
\hline High load group, n (\%) & $7(5.6 \%)$ & $8(15.7 \%)$ & $5(21.7 \%)$ & 10 (21.7\%) & $6(30 \%)$ & - \\
\hline
\end{tabular}

${ }^{*} P<0.05$ versus the normal group

CIN Cervical intraepithelial neoplasia, IQR interquartile range 
$(\mathrm{OR}=8.266,95 \%$ CI: $2.120-32.233, P=0.002)$ were both independent risk factors (Table 3 ).

\section{Discussion}

The correlation between HPV viral load and cervical lesions is poorly known, and the significance of HPV viral load in the detection and treatment of cervical lesions is still controversial $[16,18]$. Therefore, this study aimed to analyze the correlation between the high-risk HPV viral load and different cervical lesion degrees and the value of high-risk HPV viral load in the early diagnosis and prediction of cervical lesions. The results suggest that cervical lesions are closely related to high-risk HPV infection in women who underwent cervical biopsy. Higher highrisk HPV viral load in cervical lesions was associated with a higher risk of high-grade cervical lesions. Nevertheless, the high-risk HPV DNA load could be used for triage [14].

In this population, the rate of HPV positivity among the screened women was $13.5 \%$, which is a little lower than the national rate in China [21]. The patients with CIN grade 3 and cervical cancer were older than those with normal results, CIN grade 1, and CIN grade 2, which is consistent with the literature, i.e., that age is a risk factor for advanced cervical lesions $[1,4,8,19]$.

Since integrating the HPV DNA into the host cells is necessary for malignant transformation by the E6 and E7 proteins, the HPV DNA load has been suggested to be used as a marker of the risk of dysplasia and cervical cancer [16, 22]. In addition, the quantification of the DNA load could have a direct relationship with the risk of cervical lesions [23-25]. Clinical trials by Ronco et al. $[26,27]$ showed that liquid-based cytology, high-risk HPV detection using Hybrid Capture II, and biopsy in the presence of atypic squamous cells or worse was an appropriate screening strategy for cervical lesions. Many HPV infections will not lead to cervical lesions since a persistent infection is necessary for malignant transformation, and many infections are self-resolving [28]. Therefore, high viral loads should suggest persistent infections, and high viral loads indicate a lower possibility of self-resolution [29]. Hildesheim et al. [30] showed that a viral load threshold of $10 \mathrm{pg} / \mathrm{mL}$ indicated persisting HPV infection. Nevertheless, this association is still controversial [20,31]. Lorincz et al. [20] reported no association between the viral load of 13 high-risk HPVs and the risk of CIN grade 3 and cervical cancer, while Wu et al. [23] showed that the HPV-18 viral load was low in precancerous lesions but high in cervical cancer. Ronco et al. [27] showed that HPV DNA $>2 \mathrm{pg} / \mathrm{ml}$ was associated with the presence of CIN 2+, but that triage or repeat testing was necessary since some CIN lesions can regress. The present study supports the hypothesis that high-risk HPV viral loads are associated with more advanced cervical lesions. This view is supported by Long et al. [18], who showed that the viral load of HPV-16, HPV-58, and HPV-33 was associated with high-grade cervical lesions, as well as by other studies in various populations [12-18,

Table 3 Correlation between pathological types and HPV-DNA load

\begin{tabular}{|c|c|c|c|c|c|c|c|c|}
\hline & \multicolumn{4}{|l|}{ CIN I } & \multicolumn{4}{|l|}{ CIN II } \\
\hline & $\begin{array}{l}\text { Univariable OR (95\% } \\
\mathrm{Cl})\end{array}$ & $P$ & $\begin{array}{l}\text { Multivariable OR } \\
(95 \% \mathrm{Cl})\end{array}$ & $P$ & $\begin{array}{l}\text { Univariable OR (95\% } \\
\mathrm{Cl})\end{array}$ & $P$ & $\begin{array}{l}\text { Multivariable OR } \\
(95 \% \mathrm{Cl})\end{array}$ & $P$ \\
\hline Age $<30$ years & Ref & & Ref & & Ref & & Ref & \\
\hline $30-40$ years & $0.488(0.187,1.274)$ & 0.143 & $0.51(0.193,1.345)$ & 0.173 & $1.057(0.343,3.256)$ & 0.923 & $1.173(0.371,3.71)$ & 0.786 \\
\hline$\geq 40$ years & $0.966(0.432,2.158)$ & 0.932 & $0.931(0.412,2.107)$ & 0.864 & $0.523(0.16,1.71)$ & 0.283 & $0.483(0.144,1.62)$ & 0.238 \\
\hline Low load & Ref & & Ref & & Ref & & Ref & \\
\hline Moderate load & $1.803(0.879,3.698)$ & 0.108 & $1.815(0.882,3.737)$ & 0.106 & $1.822(0.664,4.998)$ & 0.244 & $1.804(0.654,4.976)$ & 0.254 \\
\hline \multirow[t]{3}{*}{ High load } & $3.905(1.285,11.869)$ & 0.016 & $3.568(1.164,10.941)$ & 0.026 & $5.857(1.561,21.973)$ & 0.009 & $6.939(1.793,26.852)$ & 0.005 \\
\hline & \multicolumn{4}{|l|}{ CIN III } & \multicolumn{4}{|l|}{ Cervical cancer } \\
\hline & $\begin{array}{l}\text { Univariable OR (95\% } \\
\mathrm{Cl})\end{array}$ & $P$ & $\begin{array}{l}\text { Multivariable OR } \\
(95 \% \mathrm{Cl})\end{array}$ & $P$ & $\begin{array}{l}\text { Univariable OR (95\% } \\
\mathrm{Cl})\end{array}$ & $P$ & $\begin{array}{l}\text { Multivariable OR } \\
(95 \% \mathrm{Cl})\end{array}$ & $P$ \\
\hline Age $<30$ years & Ref & & Ref & & Ref & & Ref & \\
\hline $30-40$ years & $1.776(0.572,5.514)$ & 0.321 & $1.92(0.602,6.124)$ & 0.271 & $1.902(0.188,19.279)$ & 0.586 & $2.122(0.206,21.864)$ & 0.527 \\
\hline$\geq 40$ years & $2.421(0.838,6.99)$ & 0.102 & $2.275(0.768,6.734)$ & 0.138 & $7.172(0.903,56.986)$ & 0.062 & $6.599(0.818,53.229)$ & 0.076 \\
\hline Low load & Ref & & Ref & & Ref & & Ref & \\
\hline Moderate load & $2.847(1.324,6.121)$ & 0.007 & $2.852(1.322,6.152)$ & 0.008 & $2.278(0.744,6.971)$ & 0.149 & $2.308(0.744,7.159)$ & 0.148 \\
\hline High load & $7.321(2.426,22.093)$ & $<0.001$ & $7.052(2.304,21.586)$ & 0.001 & $10.041(2.64,38.19)$ & 0.001 & $8.266(2.12,32.233)$ & 0.002 \\
\hline
\end{tabular}

CIN Cervical intraepithelial neoplasia, $O R$ odds ratio, $\mathrm{Cl}$ confidence interval 
32-34]. Berggrund et al. [13] showed that the high-risk HPV viral load could indicate the course of the infection and the presence of CIN grade 2, CIN grade 3, and cervical cancer. A previous study also correlated the Hybrid Capture II viral load and CIN grade [35]. Wang et al. [36] reported that single or multiple infections with HPV16/18/33/51/52/58 were associated with the risk of cervical lesions. Nevertheless, a study suggested that a single measure of HPV viral load could not reliably indicate the presence of CIN [37], and a recent study supports double-testing using the Pap test and highrisk HPV detection [38]. Luo et al. [35] suggested that a threshold of $10 \mathrm{RLU} / \mathrm{CO}$ should prompt immediate colposcopy, while 1 RLU/CO should prompt reflex testing. Therefore, future studies could consider performing serial measurements and different screening strategies.

This study has limitations. It was performed at a single center, and the sample size was relatively small, mainly because not all patients underwent Hybrid Capture II analysis. The data that could be analyzed were limited to those available in the medical charts. The exact HPV subtype was not available for many patients indicated as positive in their chart. Cytology results were not available because cytology was often performed at another lowerlevel hospital or clinic. No follow-up data were available. Additional studies are still necessary to refine our understanding of the relationship between HPV DNA load and cervical lesions. Since only high-risk HPV-positive patients were included, the frequency of high-risk HPV positivity in each pathological group could be analyzed.

\section{Conclusions}

In conclusion, in the light of the previous literature, the results suggest that cervical lesions are closely related to high-risk HPV infection in women who underwent biopsy. Higher high-risk HPV viral load in cervical lesions was associated with a higher risk of high-grade cervical lesions. Therefore, high-risk HPV viral load could be used as a marker of the risk of finding high-grade cervical lesions at biopsy.

\section{Abbreviations}

HPV: Human papillomavirus; CIN: Cervical intraepithelial neoplasia; ACOG: American College of Obstetricians and Gynecologists; RLUs: Relative light units; CO: Control values; OR: Odds ratio; Cl: Confidence interval.

\section{Acknowledgements}

Not applicable.

\section{Authors' contributions}

Yang Liu contributed to conception and design, analysis and interpretation of data, administrative technical and material support, statistical analysis, drafting, and critical revision of the manuscript for important intellectual content. Changjun Xu contributed to data acquisition, analysis and interpretation of data, statistical analysis, drafting, and critical revision of the manuscript for important intellectual content. Jing Pan contributed to the analysis and interpretation of data, statistical analysis, drafting, and critical revision of the manuscript for important intellectual content. Chunyi Sun contributed to the acquisition of data, analysis, and interpretation of data, drafting the manuscript. Honglin Zhou contributed to conception and design, data acquisition, analysis and interpretation of data, administrative technical and material support, supervision. Yushi Meng contributed to conception and design, data acquisition, analysis and interpretation of data, obtaining funding, administrative technical and material support, supervision. All authors have read and approved the final manuscript.

\section{Funding}

This work was supported by the National Natural Science Foundation of China (Grant No. 81860515); the Health Science and Technology Plan Project of Yunnan (Grant Nos. 2016NS287 and 2017NS277); the Yunnan Health Training Project of High-Level Talents (Grant No. H-201629); the Applied Basic Research Joint Special Fund Project of Yunnan Provincial Science and Technology Department-Kunming Medical University (Grant No. 2018FE001,-055); and the Yunnan Ten Thousand Youth Talent Program (Grant No. [2018]73). The sponsors had no role in the design, execution, interpretation, or writing of the study.

\section{Availability of data and materials}

The datasets used and/or analyzed during the current study are available from the corresponding author on reasonable request.

\section{Declarations}

\section{Ethics approval and consent to participate}

All methods were performed in accordance with the Declaration of Helsinki and the relevant guidelines and regulations. This study was approved by the ethics committee of the Second Affiliated Hospital of Kunming Medical University. As a retrospective study, informed consent was exempted by the ethics committee of the Second Affiliated Hospital of Kunming Medical University.

\section{Consent for publication}

Not applicable.

\section{Competing interests}

The authors declare that they have no competing interests.

\section{Author details}

'Department of Reproduction, The Second Affiliated Hospital of Kunming Medical University, Kunming, China. ${ }^{2}$ Department of Reproductive Medicine, People's Hospital of Yuxi City, Yuxi, China. ${ }^{3}$ Department of Gynecology, The Second Affiliated Hospital of Kunming Medical University, No.374 Yunnan-Burma Avenue, Kunming 650101, China.

Received: 25 April 2021 Accepted: 23 September 2021

Published online: 08 October 2021

\section{References}

1. World Health Organization, International Agency for Research on Cancer. Cervical cancer. https://www.who.int/cancer/prevention/diagnosis-scree ning/cervical-cancer/en/. Accessed April 8, 2020.

2. Bray F, Ferlay J, Soerjomataram I, Siegel RL, Torre LA, Jemal A. Global cancer statistics 2018: GLOBOCAN estimates of incidence and mortality worldwide for 36 cancers in 185 countries. CA Cancer J Clin. 2018:68:394-424.

3. Song B, Ding C, Chen W, Sun H, Zhang M, Chen W. Incidence and mortality of cervical cancer in China, 2013. Chin J Cancer Res. 2017;29:471-6.

4. Arbyn M, Weiderpass E, Bruni L, de Sanjose S, Saraiya M, Ferlay J, et al. Estimates of incidence and mortality of cervical cancer in 2018: a worldwide analysis. Lancet Glob Health. 2020;8:e191-203.

5. Feng RM, Zong YN, Cao SM, Xu RH. Current cancer situation in China: good or bad news from the 2018 Global Cancer Statistics? Cancer Commun (Lond). 2019;39:22. 
6. Meyer MF, Huebbers CU, Siefer OG, Vent J, Engbert I, Eslick GD, et al. Prevalence and risk factors for oral human papillomavirus infection in 129 women screened for cervical HPV infection. Oral Oncol. 2014;50:27-31.

7. Paz-Zulueta M, Alvarez-Paredes L, Rodriguez Diaz JC, Paras-Bravo P, Andrada Becerra ME, Rodriguez Ingelmo JM, et al. Prevalence of high-risk HPV genotypes, categorised by their quadrivalent and nine-valent HPV vaccination coverage, and the genotype association with high-grade lesions. BMC Cancer. 2018;18:112.

8. Small W Jr, Bacon MA, Bajaj A, Chuang LT, Fisher BJ, Harkenrider MM, et al. Cervical cancer: a global health crisis. Cancer. 2017;123:2404-12.

9. Zampronha Rde A, Freitas-Junior R, Murta EF, Michelin MA, Barbaresco AA, Adad SJ, et al. Human papillomavirus types 16 and 18 and the prognosis of patients with stage I cervical cancer. Clinics (Sao Paulo). 2013;68:809-14.

10. Skoulakis A, Fountas S, Mantzana-Peteinelli M, Pantelidi K, Petinaki E. Prevalence of human papillomavirus and subtype distribution in male partners of women with cervical intraepithelial neoplasia (CIN): a systematic review. BMC Infect Dis. 2019;19:192.

11. Findik S, Findik S, Abuoglu S, Cihan FG, Ilter H, lyisoy MS. Human papillomavirus (HPV) subtypes and their relationships with cervical smear results in cervical cancer screening: a community-based study from the central Anatolia region of Turkey. Int J Clin Exp Pathol. 2019;12:1391-8.

12. Xi LF, Hughes JP, Castle PE, Edelstein ZR, Wang C, Galloway DA, et al. Viral load in the natural history of human papillomavirus type 16 infection: a nested case-control study. J Infect Dis. 2011;203:1425-33.

13. Berggrund M, Gustavsson I, Aarnio R, Hedlund-Lindberg J, Sanner K, Wikstrom I, et al. HPV viral load in self-collected vaginal fluid samples as predictor for presence of cervical intraepithelial neoplasia. Virol J. 2019;16:146.

14. Dong B, Sun P, Ruan G, Huang W, Mao X, Kang Y, et al. Type-specific high-risk human papillomavirus viral load as a viable triage indicator for high-grade squamous intraepithelial lesion: a nested case-control study. Cancer Manag Res. 2018;10:4839-51.

15. Del Rio-Ospina L, Soto-De Leon SC, Camargo M, Moreno-Perez DA, Sanchez R, Perez-Prados A, et al. The DNA load of six high-risk human papillomavirus types and its association with cervical lesions. BMC Cancer. 2015;15:100.

16. Shen G, Cheng J, Wang Y, Zhou P, Zhang G. Viral DNA load of high-risk human papilloma virus is closely associated with the grade of cervical lesions. Int J Clin Exp Med. 2014;7:5826-31.

17. Liang Y, Chen M, Qin L, Wan B, Wang H. A meta-analysis of the relationship between vaginal microecology, human papillomavirus infection and cervical intraepithelial neoplasia. Infect Agent Cancer. 2019;14:29.

18. Long W, Yang Z, Li X, Chen M, Liu J, Zhang Y, et al. HPV-16, HPV-58, and HPV-33 are the most carcinogenic HPV genotypes in Southwestern China and their viral loads are associated with severity of premalignant lesions in the cervix. Virol J. 2018;15:94.

19. Practice Bulletin No. 168 Summary: cervical cancer screening and prevention. Obstet Gynecol. 2016;128:923-5.

20. Lorincz AT, Castle PE, Sherman ME, Scott DR, Glass AG, Wacholder S, et al. Viral load of human papillomavirus and risk of CIN3 or cervical cancer. Lancet. 2002;360:228-9.

21. Zeng Z, Yang H, Li Z, He X, Griffith CC, Chen X, et al. Prevalence and genotype distribution of HPV infection in China: analysis of 51,345 HPV genotyping results from China's largest CAP certified laboratory. J Cancer. 2016;7:1037-43

22. Dalstein V, Riethmuller D, Pretet JL, Le Bail CK, Sautiere JL, Carbillet JP, et al. Persistence and load of high-risk HPV are predictors for development of high-grade cervical lesions: a longitudinal French cohort study. Int J Cancer. 2003;106:396-403.

23. Wu Z, Qin Y, Yu L, Lin C, Wang H, Cui J, et al. Association between human papillomavirus (HPV) 16, HPV18, and other HR-HPV viral load and the histological classification of cervical lesions: Results from a large-scale cross-sectional study. J Med Virol. 2017;89:535-41.
24. Segondy M, Ngou J, Kelly H, Omar T, Goumbri-Lompo O, Doutre S, et al. Diagnostic value of human papillomavirus (HPV) 16 and HPV 18 viral loads for the detection of high-grade cervical intraepithelial neoplasia (CIN2+) in a cohort of African women living with HIV. J Clin Virol. 2018;99-100:79-83.

25. Sherman ME, Schiffman M, Cox JT. Effects of age and human papilloma viral load on colposcopy triage: data from the randomized atypical squamous cells of undetermined significance/low-grade squamous intraepithelial lesion triage study (ALTS). J Natl Cancer Inst. 2002;94:102-7.

26. Ronco G, Giorgi-Rossi P, Carozzi F, Dalla Palma P, Del Mistro A, De Marco L, et al. Human papillomavirus testing and liquid-based cytology in primary screening of women younger than 35 years: results at recruitment for a randomised controlled trial. Lancet Oncol. 2006;7:547-55.

27. Ronco G, Giorgi-Rossi P, Carozzi F, Confortini M, Dalla Palma P, Del Mistro A, et al. Results at recruitment from a randomized controlled trial comparing human papillomavirus testing alone with conventional cytology as the primary cervical cancer screening test. J Natl Cancer Inst. 2008;100:492-501.

28. Schlecht NF, Kulaga S, Robitaille J, Ferreira S, Santos M, Miyamura RA, et al. Persistent human papillomavirus infection as a predictor of cervical intraepithelial neoplasia. JAMA. 2001;286:3106-14.

29. Nobbenhuis MA, Helmerhorst TJ, van den Brule AJ, Rozendaal L, Voorhorst FJ, Bezemer PD, et al. Cytological regression and clearance of high-risk human papillomavirus in women with an abnormal cervical smear. Lancet. 2001;358:1782-3.

30. Hildesheim A, Schiffman MH, Gravitt PE, Glass AG, Greer CE, Zhang T, et al. Persistence of type-specific human papillomavirus infection among cytologically normal women. J Infect Dis. 1994;169:235-40.

31. Sun CA, Liu JF, Wu DM, Nieh S, Yu CP, Chu TY. Viral load of high-risk human papillomavirus in cervical squamous intraepithelial lesions. Int J Gynaecol Obstet. 2002:76:41-7.

32. Josefsson AM, Magnusson PK, Ylitalo N, Sorensen P, Qwarforth-Tubbin P, Andersen PK, et al. Viral load of human papilloma virus 16 as a determinant for development of cervical carcinoma in situ: a nested case-control study. Lancet. 2000;355:2189-93.

33. Ylitalo N, Sorensen P, Josefsson AM, Magnusson PK, Andersen PK, Ponten $J$, et al. Consistent high viral load of human papillomavirus 16 and risk of cervical carcinoma in situ: a nested case-control study. Lancet. 2000;355:2194-8.

34. Moberg M, Gustavsson I, Wilander E, Gyllensten U. High viral loads of human papillomavirus predict risk of invasive cervical carcinoma. Br J Cancer. 2005:92:891-4.

35. Luo H, Belinson JL, Du H, Liu Z, Zhang L, Wang C, et al. Evaluation of viral load as a triage strategy with primary high-risk human papillomavirus cervical cancer screening. J Low Genit Tract Dis. 2017;21:12-6.

36. Wang Z, Gu Y, Wang H, Chen J, Zheng Y, Cui B, et al. Distribution of cervical lesions in high-risk HPV (hr-HPV) positive women with ASC-US: a retrospective single-center study in China. Virol J. 2020;17:185.

37. Constandinou-Williams C, Collins SI, Roberts S, Young LS, Woodman CB, Murray PG. Is human papillomavirus viral load a clinically useful predictive marker? a longitudinal study. Cancer Epidemiol Biomarkers Prev. 2010;19:832-7.

38. Wu T, Chen X, Zheng B, Li J, Xie F, Ding X, et al. Previous Papanicolaou and hybrid capture 2 human papillomavirus testing results of 5699 women with histologically diagnosed cervical intraepithelial neoplasia 2/3. J Am Soc Cytopathol. 2019;8:206-11.

\section{Publisher's Note}

Springer Nature remains neutral with regard to jurisdictional claims in published maps and institutional affiliations. 